\title{
ANÁLISE DA CONCESSÃO DE INCENTIVOS FISCAIS PARA PRODUÇÃO DE AGROTÓXICOS SOB O VIÉS DO PRINCÍPIO DA SELETIVIDADE TRIBUTÁRIA
}

\section{VALMIR CÉSAR POZZETTI}

Doutor em Biodireito/Direito Ambiental pela Université de Limoges/França. Mestre em Direito do Urbanismo e Meio ambiente pela Université de Limoges/França. Professor Adjunto da UFAM - Univ. Federal do Amazonas e da UEA - Universidade do Estado do Amazonas.

\section{MARCELO ANTUNES SANTOS}

Mestrando do PPGDA - Programa de Pós Graduação em direito ambiental da UEA Universidade do Estado do Amazonas.

\section{VINICIUS RIBEIRO DE SOUZA}

Mestrando do PPGDA - Programa de Pós Graduação em direito ambiental da UEA Universidade do Estado do Amazonas.

\section{OBJETIVOS DO TRABALHO}

A pesquisa em questão teve como mola propulsora a indignação decorrente da aprovação dos incentivos fiscais para a produção de agrotóxicos por meio de cláusulas especificas do Convênio nº 100/97 do Conselho Nacional de Política Fazendária (Confaz) e o Decreto 7.660/2011, bem como pelo debate que se se formou a partir do marco citado.

Delimitado os pressupostos motivadores da pesquisa, objetiva-se por meio do presente trabalho; i) avaliar os incentivos fiscais concedidos para produção de agrotóxicos a partir do princípio da seletividade tributária, ii) relacionar os impactos 


\section{Personalidade Acadêmica Homenageada:}

\section{Carlos Aurélio Mota de Souza (Universidade Ibirapuera - UNIB)}

ambientais decorrentes da utilização dos agrotóxicos com a extrafiscalidade tributária e por fim, iii) avaliar as políticas de incentivo implementadas a partir da ideia de desenvolvimento sustentável esculpida no texto Constitucional.

\section{METODOLOGIA UTILIZADA}

A investigação realizada se utilizou do método qualitativo, com levantamento e estudo bibliográfico sobre o tema, leitura dos debates em trâmite no âmbito judicial e demais discussões sobre a matéria.

A aprovação de incentivos fiscais à produção de agrotóxicos, concedidos sob o manto do desenvolvimento da atividade agrária, reflete possível afronta à Constituição Federal, de modo especial nos seus artigos 170 e 225, atropelando o ideal de desenvolvimento sustentável, desvirtuando ainda a ideia de extrafiscalidade dos tributos e o princípios da seletividade e essencialidade tributária. Nota-se deste modo, um desequilíbrio entre os meios utilizados para se alcançar a maior produtividade do agronegócio e a manutenção do meio ambiente equilibrado nos termos preconizados pelo legislador constituinte. Ao tratar do meio ambiente e seu papel na manutenção e equilíbrio da vida leciona José Afonso da Silva que "[...] o meio ambiente é a interação do conjunto de elementos naturais, artificiais e culturais que propiciem o desenvolvimento equilibrado da vida em todas as suas formas". ${ }^{1 .}$

\section{REVISÃO DE LITERATURA}

A economia brasileira tem fortes raízes no agronegócio, de modo que inegável a importância deste segmento para manutenção e melhoria da qualidade de vida da sociedade brasileira. A partir dessas raízes nota-se uma forte tendência e interesse dos governos e dos grandes latifundiários em expandir a capacidade de produção agrícola num curto espaço de tempo, sem contudo voltar os olhos para os impactos

1 SILVA, José Afonso da. Curso de Direito Constitucional Positivo. 25.ed. São Paulo: Malheiros, 2005. p.96 


\section{Personalidade Acadêmica Homenageada:}

Carlos Aurélio Mota de Souza (Universidade Ibirapuera - UNIB)

ambientais decorrentes de tais medidas. A política de incentivos fiscais com foco na produção de agrotóxicos se insere nesse contexto.

Como modelos de instrumentos normativo que regulam o assunto pesquisado temos o Convênio № 100/97 do Conselho Nacional de Política Fazendária (Confaz) em suas clausulas $1^{\text {a }}$ e $3^{\text {a }}$ e $\circ$ Decreto 7.660/2011. Tais dispositivos concedem benefícios fiscais ao mercado de agrotóxicos, com redução de $60 \%$ da base de cálculo do ICMS, além da isenção total do IPI de determinados tipos de agrotóxicos.

Ao promover os incentivos constatados, utilizou se o poder público do caráter extrafiscal dos tributos em destaque. Acerca do tema, leciona Machado que "[...] o tributo é extrafiscal quando seu objetivo principal é a interferência no domínio econômico, para buscar um efeito diverso da simples arrecadação de recursos financeiros"2. A partir dessa reflexão, tem-se que a seletividade permite que o Estado influencie o comportamento de consumo dos cidadãos e balize o mercado e a produção, sendo pois, uma forma de extrafiscalidade.

Não obstante a singularidade dos tributos mencionados no que tange a seletividade das alíquotas que Ihes são aplicáveis, tem-se que o fomento por parte do poder público da comercialização dos agrotóxicos por meios dos incentivos concedidos é contrário ao ideal de desenvolvimento sustentável, bem como ao princípio da seletividade que rege o sistema de tributação vigente. Ao discorrer sobre o princípio da seletividade aplicável às espécies cabíveis leciona Carraza que:

Os tributos, de um modo geral, são utilizados como instrumento de fiscalidade, servindo basicamente, pois, para carrear dinheiro aos cofres públicos.O IPI e o ICMS, pelo contrário, devem necessariamente ser instrumentos de extrafiscalidade, a teor dos já citados arts. 153, § $3^{\circ}$, I e 155, $\S 2^{\circ}$, III, da CF. Salientamos que estas normas constitucionais, mandando que tais impostos sejam seletivos, não estão dando uma mera faculdade ao legislador, mas, pelo contrário, estão lhe impondo um inarredável dever, de cujo cumprimento ele não pode se furtar. (...) Portanto, a seletividade, no IPI e no ICMS, é obrigatória. Ou, seguindo a trilha constitucional, estes tributos devem ser seletivos, em função da essencialidade do produto industrializado (IPI) ou das mercadorias ou serviços (ICMS). Estamos confirmando, destarte, que o IPI e o ICMS devem ser utilizados como instrumentos de ordenação político-econômica, estimulando a prática de operações (com produtos

${ }^{2}$ MACHADO, Hugo de Brito. Curso de Direito Tributário. São Paulo: Malheiros, 2009, p. 96. 


\title{
Personalidade Acadêmica Homenageada: \\ Carlos Aurélio Mota de Souza (Universidade Ibirapuera - UNIB)
}

industrializados ou mercadorias) ou serviços havidos por necessários, úteis ou convenientes à sociedade e, em contranota, onerando outros que não atendam tão de perto o interesse coletivo ${ }^{3}$.

Tem-se desta forma que o princípio estudado, ao objetivar atingir serviços essenciais à coletividade pressupõe a observância da preservação do meio ambiente e dos demais aspectos da vida humana, tal como o direito a saúde. Uma vez distanciados dos direitos mencionados, torna se evidente a ausência de adequação dos benefícios concedidos ao que preconiza o legislador constituinte. Conforme preceituou Lemes \& Paiva:

O meio ambiente foi protegido pela Constituição Federal de 1988, que destinou um capítulo específico para concretizar o meio ambiente ecologicamente equilibrado como um direito de todos, vinculado à qualidade de vida humana ${ }^{4}$.

Neste sentido, Pozzetti, ao comentar sobre alimentos transgênicos, também dependentes de agrotóxicos, esclarece:

\begin{abstract}
Ao Estado - Administração Pública - como agente garantidor da ordem econômica e social, cabe a responsabilidade pela liberação e fiscalização da oferta desses alimentos no mercado consumidor. Para tal mister, há uma série de regras e imposições legais que o agente público deve observar para permitir o processo, desde a construção em laboratório da semente, plantio e meio ambiente, até a chegada à mesa do consumidor ${ }^{5}$.
\end{abstract}

O modelo econômico que se funda agronegócio, beneficiado pelos incentivos fiscais no que tange a produção de pesticidas fere frontalmente os direitos fundamentais à vida, à saúde e ao meio ambiente equilibrado. Dispôs o constituinte

3 CARRAZA. Roque Antônio. Curso de Direito Constitucional Tributário. 20aํ ed. São Paulo: Malheiros, 2004. pg. 89/90.

4 LEMES, João Vitor Martins; PAIVA, Mônica Ribeiro de. Agrotóxicos e supressão dos Direitos Fundamentais: Análise do Conflito Socioambiental de São José Do Pontal em Rio Verde, Goiás. Direito Ambiental II. Ed. CONPEDI 2014. P. 242. Disponível em < http://www. publicadireito.com.br/artigos/?cod=3dce18d1998152ee> Acesso em 20 mai 2018.

5 POZZETTI, Valmir César. Responsabilidades da administração pública na liberação de alimentos transgênicos no Brasil. Cadernos de Dereito Actual № 7 Extraordinario (2017), pp. 185-204 ·ISSN 2340860X - -ISSNe 2386-5229. Disponivel em < file:///C:/Users/Valmir\%20Pozzetti/Downloads/223-586-1PB.pdf>, consultada em 20 mai 2018. P.186 


\title{
Personalidade Acadêmica Homenageada:
}

Carlos Aurélio Mota de Souza (Universidade Ibirapuera - UNIB)

originário em seu artigo 225 que: "Todos têm direito ao meio ambiente ecologicamente equilibrado, bem de uso comum do povo e essencial à sadia qualidade de vida, impondo-se ao Poder Público e à coletividade o dever de defendê-lo e preservá-lo para as presentes e futuras gerações" ${ }^{6}$

Dessa forma, Pozzetti conclui que:

\begin{abstract}
Assim, se a Administração Pública não observar os requisitos legais no momento da liberação da atividade e esta atividade trouxer prejuízos, seja ao meio ambiente ou ao consumidor, o Estado é responsável pelos prejuízos causados ${ }^{7}$.
\end{abstract}

Assim, temos que o as políticas de incentivo à produção e utilização de agrotóxicos, por ter como objeto agente causador de dano ao meio ambiente e à saúde humana é incompatível com o princípio da seletividade tributária, do direito ao meio ambiente equilibrado, da saúde humana e do próprio princípio da dignidade da pessoa humana, esculpido no artigo 1ำ, III da Constituição federal. É certo que se a questão ambiental não for sopesada in casu, a consequência será um dano ambiental, como já se noticia, haja vista notória tendência ao desequilíbrio dos recursos ambientais provocados pela ação humana e conduta pública constada.

\section{RESULTADOS OBTIDOS OU ESPERADOS}

A presente pesquisa, a partir do cenário atual de intensa utilização de agrotóxicos no agronegócio, buscou avaliar possível incompatibilidade dos incentivos fiscais concedidos pelo poder público com o sistema jurídico vigente, fazendo portanto um paralelo com o princípio da seletividade tributária.

Pela análise bibliográfica empreendida, constatou se que embora permeado de caráter extrafiscal, as espécies tributárias utilizadas como instrumento de realização das políticas de incentivo tem suas alíquotas relacionadas a essencialidade dos serviços objeto de tributação.

6 BRASIL, Constituição da República Federativa do Brasil de 1988. Congresso Nacional, Brasília, 1988.

7 idem. P.186 


\section{Personalidade Acadêmica Homenageada:}

\section{Carlos Aurélio Mota de Souza (Universidade Ibirapuera - UNIB)}

Deste modo, a conduta de incentivo estatal pesquisada fomenta a atividade, produção e utilização de produto prejudicial ao meio ambiente e a saúde humana, como restou demonstrado. Referida constatação evidencia a incoerência da política de incentivo neste segmento, haja vista que os agrotóxicos não se revestem do caráter essencial previsto pelo legislador constituinte nos artigos 153 e 155 da Constituição Federali.

Assim, restando afastado o caráter essencial da atividade empreendida, ora beneficiada, tem se como ilegal a aplicação do princípio da seletividade como como mecanismo que beneficie a produção e uso dos referidos pesticidas.

A presente pesquisa, surgida a partir de uma inquietação ainda incipiente sobre a temática, demonstrou por meio de uma análise mais detida, sobretudo pela referencial bibliográfico avaliado, que as premissas iniciais se confirmam de modo que que os incentivos fiscais relacionados a produção e utilização de agrotóxicos ferem frontalmente o princípio da essencialidade e demais direitos constitucionais, vida, saúdem dignidade da pessoa humana, alhures destacados.

\section{TÓPICOS CONCLUSIVOS}

Conforme se verificou, a temática estudada é assunto atual, já permeia o debate jurídico e de demais segmentos da sociedade, haja vista a sua extrema relevância do ponto de vista da qualidade da vida e saúde humana e do meio ambiente.

Os objetivos da pesquisa foram cumpridos uma vez que se analisou a (i) legalidade das medidas implementadoras de incentivos fiscais concedidos na produção de agrotóxicos, percorrendo para tanto o princípio da seletividade tributária e o caráter extrafiscal dos tributos elencados.

Notou-se no curso da pesquisa que as medidas estatais avaliadas, ao causar efeitos danosos à saúde humana e ao meio ambiente, ferem a constituição federal e os princípios de natureza tributária que permeia seu texto.

A questão aqui discutida se encontra, em termos, sob análise do Supremo Tribunal Federal, por meio da Ação Direta de Inconstitucionalidade (ADI) 5553, 
Personalidade Acadêmica Homenageada:

Carlos Aurélio Mota de Souza (Universidade Ibirapuera - UNIB)

ajuizada pelo Partido Socialismo e Liberdade (PSOL) em 2016, onde se questiona as cláusulas $1^{\text {a }}$ e $3^{\text {a }}$ do Convênio ํํำ 100/97 do Conselho Nacional de Política Fazendária (Confaz) e o Decreto № 7.660/2011, o que corrobora com a atualidade e relevância jurídica do objeto pesquisado.

Conclui-se que os incentivos fiscais a agrotóxicos lesam o cidadão e que os mecanismos jurídicos que se propõe a tal finalidade são eivados de inconstitucionalidade, sendo diametralmente opostos aos princípios da seletividade e aos ideais de preservação ambiental, insculpidos expressamente no texto constitucional. 